\title{
Polyphasic analysis indicates that Lactobacillus salivarius subsp. salivarius and Lactobacillus salivarius subsp. salicinius do not merit separate subspecies status
}

\author{
Yin Li, Emma Raftis, Carlos Canchaya, Gerald F. Fitzgerald, \\ Douwe van Sinderen and Paul W. O'Toole \\ Department of Microbiology and Alimentary Pharmabiotic Centre, University College Cork, \\ Ireland
}

Correspondence

Paul W. O'Toole

pwotoole@ucc.ie

\begin{abstract}
Lactobacillus salivarius Rogosa et al. 1953 was described as a homofermentative lactobacillus with two varieties: salivarius, typified inter alia by the ability to ferment rhamnose, and salicinius, characterized by the ability to ferment the glucoside salicin. These varieties have become accepted as subspecies divisions. We have examined the relatedness of $32 \mathrm{~L}$. salivarius strains by a polyphasic approach. Carbohydrate fermentation profile analysis did not support clear distinction of the two subspecies. L. salivarius UCC118 was shown to be facultatively heterofermentative, confirming in silico genome analysis. 16S rRNA gene sequences and 16S-23S rRNA intergenic spacer region sequences provided no discrimination between any of the strains or subspecies. Broad subdivisions were distinguishable by pulsed-field gel genomic digest patterns, but they did not allow subspecific or phenotypic distinctions. A phylogeny based upon groEL gene sequences was discordant with rhamnose or salicin fermentation data for many taxa, and no reliable phenotypic correlations could be established. In the absence of meaningful taxonomic criteria, we therefore propose that Lactobacillus salivarius comprises a single species with no infraspecific taxa. Based on the present study and literature data, an emended description of the species Lactobacillus salivarius is provided.
\end{abstract}

Lactobacillus salivarius was first isolated as part of a survey of human oral lactobacilli (Rogosa et al., 1953) and is commonly found in the oral cavity and gastrointestinal tract of humans (Ahrne et al., 1998; Heilig et al., 2002; Molin et al., 1993; Rogosa et al., 1953) and other animals such as the hamster (Rogosa et al., 1953). In the original study defining the species L. salivarius, Rogosa and colleagues appear to have based their classification mainly upon 11 isolates from eight different human subjects, although 106 strains from hamsters were also investigated. L. salivarius constituted a clearly separate species from other oral lactobacilli then being characterized, including Lactobacillus cellobiosus (Rogosa et al., 1953). Two varieties of $L$. salivarius were recognized in this report, 'Lactobacillus salivarius var. salivarius' and 'Lactobacillus salivarius var. salicinius'. These were distinguished by fermentation profiles. ' $L$.

\footnotetext{
Abbreviations: ISR, intergenic spacer region; PFGE, pulsed-field gel electrophoresis.

The GenBank/EMBL/DDBJ accession numbers for the 16S rRNA gene sequences of strains AH4331, DSM 20555', NCIMB 702343 and NCIMB 8817 are D0901732-D0901735, and the accession numbers of the groEL sequences obtained in this study are detailed in Table 1.
}

salivarius var. salivarius' produced significant acidity in glucose, laevulose, melibiose, trehalose, lactose, mannitol, mannose, raffinose, sucrose, galactose, maltose, rhamnose and sorbitol. It did not ferment arabinose, xylose, cellobiose, melezitose, methyl $\alpha$-D-glucoside, methyl $\alpha$-D-mannoside, salicin, glycerol or sorbose (Rogosa et al., 1953). The second variety differed from the 'type variety' in that it fermented salicin but not rhamnose.

No subsequent, more comprehensive investigation of $L$. salivarius has appeared in literature since the original description (Rogosa et al., 1953) and a subsequent 1959 Lactobacillus classification paper, which also proposed $L$. salivarius species varieties (Rogosa \& Sharpe, 1959). However, Mitsuoka (1969) distinguished five major biotypes among $13 \mathrm{~L}$. salivarius strains, which do not correspond readily to the varieties proposed by Rogosa et al. (1953). This may be because the strains were from pigs and chickens, as well as humans. The type I biotype most closely resembled ' $L$. salivarius var. salivarius', but almost half of the salicin-fermenting strains also fermented rhamnose and thus could not be assigned to a subspecies according to the criterion proposed by Rogosa et al. (1953). Interestingly, two distinctive biotypes $(\mathrm{Va}, \mathrm{Vb})$, which 
ferment ribose, cellobiose and amygdalin, that were previously grouped within the $L$. salivarius species by Mitsuoka (1969), were later reclassified as Lactobacillus animalis on the basis of DNA-DNA relatedness (Fujisawa \& Mitsuoka, 1996). We recently sequenced the genome of $L$. salivarius subsp. salivarius UCC118 (Claesson et al., 2006), a human isolate with probiotic properties (Dunne et al., 1999). This strain ferments rhamnose because it has genes on a megaplasmid (pMP118) that encode rhamnulokinase, L-rhamnose isomerase and rhamnulose-1-phosphate aldolase. The inability of strain UCC118 to ferment salicin is due to the absence of 6-phospho- $\beta$-glucosidase, which converts salicin 6-phosphate to glucose 6-phosphate (Claesson et al., 2006).

The two varieties of $L$. salivarius described by Rogosa $e t$ al. (1953) were included in the Approved Lists of Bacterial Names as subspecies (Skerman et al., 1980; Kandler \& Weiss, 1986); the term 'variety' no longer has standing in nomenclature under the Bacteriological Code (Rule 5c; Lapage et al., 1992). Culture collection descriptions of the two subspecies also refer to the original isolation. Recent sequence analysis of the 16S-23S rRNA intergenic spacer region (ISR) of the type strains of the two subspecies found them to be $100 \%$ identical (Song et al., 2000) and most closely related to Lactobacillus reuteri, Lactobacillus fermentum and Lactobacillus plantarum. The sequences of the ISR flanking the 23S rRNA genes of the two subspecies were also identical. The taxonomic basis for infraspecific subdivision of $L$. salivarius strains was therefore open to question. Sequencing of the genome of $L$. salivarius UCC118 revealed the presence of a complete pentose phosphate pathway (Claesson et al., 2006), including two genes encoding phosphoketolase, a key enzyme involved in heterofermentation (Kandler, 1983). This suggested that this strain is facultatively heterofermentative, which challenges the generally accepted view that $L$. salivarius is an obligately homofermentative lactic acid bacterium. (Badet et al., 2001; Koll-Klais et al., 2005; London, 1976). Preliminary analysis of fermentation end products confirmed that $L$. salivarius UCC118 is indeed heterofermentative (Claesson et al., 2006).

To clarify the infraspecific classification of $L$. salivarius, we employed a polyphasic approach to re-examine the relatedness of strains from both presumptive subspecies. Thirty-two strains from a variety of culture collections were examined (Table 1), which included 15 strains of L. salivarius subsp. salivarius, 12 strains of $L$. salivarius subsp. salicinius and five strains unassigned to a subspecies. For most strains, the rationale for subspecies definition was unclear. Twenty-one strains were of human origin, the remainder, except for a single food isolate, being derived from a variety of mammalian or avian hosts.

The carbohydrate fermenting profile of all strains was determined using API $50 \mathrm{CH}$ strips in conjunction with API 50 CHL medium (bioMérieux). Freshly grown colonies of respective strains were harvested and resuspended in sterile water to achieve a cell density of $10^{10}$ c.f.u. $\mathrm{ml}^{-1}$. An aliquot of the cell suspension $(200 \mu \mathrm{l})$ was inoculated into $10 \mathrm{ml}$ API 50 CHL medium and mixed gently by inversion; $120 \mu \mathrm{l}$ of this suspension was inoculated into API $50 \mathrm{CH}$ strips that were then overlaid with paraffin to maintain anaerobic conditions. Incubation was carried out at $37^{\circ} \mathrm{C}$ for $48 \mathrm{~h}$. Fermentation was indicated by a colour change from purple to yellow in the strip cupule. As the inoculum of different strains was adjusted to identical levels, we were able to use the colour change to express the fermentation capabilities semi-quantitatively. The colour changes that we observed were from blue (lack of fermentation) to bottle-green, green, yellow-green, aqua and yellow (complete fermentation). These colour changes were accordingly converted to numerical values in a grey scale (as indicated in the legend to Fig. 1) to facilitate the construction of a dendrogram using BioNumerics software (Applied Maths). This employs the Bray-Curtis method to compare the matrix distance and the UPGMA method to build a similarity tree from the matrix distance (Fig. 1). Seven strains classified as belonging to subspecies salivarius did not ferment rhamnose, a supposedly diagnostic criterion, and seven more fermented rhamnose very slowly, with only one rapid rhamnose fermenter. Only one subspecies salivarius strain fermented salicin. However, almost half of the supposedly subspecies salicinius strains fermented salicin, and five out of 12 strains fermented rhamnose as quickly as the slow subspecies salivarius fermenters. None of the carbohydrate fermentation profiles agreed unequivocally with current subspecies strain assignments, nor did any of them suggest a consistent novel subspecies division. Interestingly, ribose fermentation was restricted to three strains, all of which were isolated from humans locally in Cork, Ireland. These strains were grouped in a clearly separated branch from the others, as shown in Fig. 1. Pentose fermentation is usually indicative of heterofermentative ability (Kandler, 1983). We determined the fermentation end products of the sequenced strain UCC118 to validate the correlation between its ribose fermentation and heterofermentative ability. The strain was grown in glucosefree MRS medium supplemented with glucose, fructose or ribose (100 mM each). Following growth at $37^{\circ} \mathrm{C}$ for $16 \mathrm{~h}$, the fermentation end products were determined by HPLC. Sampling was performed by taking $1 \mathrm{ml}$ culture supernatant and filtering through a $0.45 \mu \mathrm{m}$ sterile syringe filter into a HPLC vial stored on ice. Samples were then analysed on an LKB Bromma 2150 HPLC system equipped with a Shodex RI-71 refractive index detector and a Highchrom heating block. A Rezex $8 \mu 8 \%$ organic acid column $(300 \times 7 \cdot 8 \mathrm{~mm}$; Phenomenex) was used, with $0.005 \mathrm{M} \mathrm{H}_{2} \mathrm{SO}_{4}$ as the mobile phase, at a flow rate of $0.6 \mathrm{ml} \mathrm{min}{ }^{-1}$. The temperature of the column was maintained at $65^{\circ} \mathrm{C}$ and the injection volume was $20 \mu \mathrm{l}$. While the major end product was still lactate $(140 \pm 15 \mathrm{mM})$ when grown on hexoses (glucose or fructose), ethanol $(1 \cdot 8 \pm 0 \cdot 5 \mathrm{mM})$ was detected when grown on glucose, and ethanol $(1 \cdot 2 \pm 0.2 \mathrm{mM})$ and acetate $(4 \cdot 9 \pm 0.4 \mathrm{mM})$ were detected when grown on fructose. In addition, lactate $(125 \pm 8 \mathrm{mM})$, ethanol $(2 \cdot 0 \pm 0 \cdot 3 \mathrm{mM})$ 
Table 1. Strains used in this study

CCUG, Culture Collection of the University of Göteborg; DSM, Deutsche Sammlung von Mikroorganismen und Zellkulturen GmbH; JCM, Japan Collection of Microorganisms; LMG, Laboratorium voor Microbiologie, Universiteit Gent; NCIMB, National Collections of Industrial Food and Marine Bacteria. Type strains are indicated by a superscript T.

\begin{tabular}{|c|c|c|c|}
\hline Strain & Origin & Reference & groEL accession number \\
\hline UCC118 & Human ileal-caecal region & Claesson et al. (2006) & DQ444330 \\
\hline AH4331 & Human ileal-caecal region & & DQ444347 \\
\hline AH43310 & Human ileal-caecal region & & DQ444333 \\
\hline DSM $20555^{\mathrm{T}}$ & Human saliva & Rogosa et al. (1953) & DQ444343 \\
\hline NCIMB 8816 & Italian human saliva & & DQ444359 \\
\hline NCIMB 8817 & Turkey faeces & & DQ444341 \\
\hline NCIMB 8818 & St. Ivel cheese & & DQ444332 \\
\hline CCUG 27530B & Human abdomen, abscess & & DQ444331 \\
\hline \multicolumn{4}{|c|}{ Lactobacillus salivarius subsp. salicinius } \\
\hline DSM $20554^{\mathrm{T}}$ & Human saliva & Rogosa et al. (1953) & DQ444350 \\
\hline NCIMB 702343 & Unknown & & DQ444339 \\
\hline CCUG 44481 & Bird & & DQ444352 \\
\hline CCUG 47171 & Human tooth plaque & & DQ444337 \\
\hline CCUG 47826 & Human blood, 55-year-old woman & & DQ444336 \\
\hline JCM 1040 & Human intestine & Mitsuoka (1969) & DQ444357 \\
\hline JCM 1042 & Human intestine & Mitsuoka (1969) & DQ444360 \\
\hline JCM 1044 & Human intestine & Mitsuoka (1969) & DQ444361 \\
\hline JCM 1045 & Human intestine & Mitsuoka (1969) & DQ444345 \\
\hline JCM 1046 & Swine intestine & Mitsuoka (1969) & DQ444344 \\
\hline L21 & Unknown & & DQ444358 \\
\hline
\end{tabular}

and acetate $(27 \cdot 0 \pm 1 \cdot 2 \mathrm{mM})$ were detected when grown on ribose. These data collectively confirm that strain UCC118 is a facultatively heterofermentative Lactobacillus, which is consistent with our previous in silico genome analysis and preliminary analysis of fermentation products (Claesson et al., 2006). The discovery of L. salivarius strains that exhibit heterofermentative metabolism suggests that this species should not be considered as obligately homofermentative.

As the API 50 carbohydrate fermentation profile did not give discriminative separation for subspecies, we employed several molecular techniques in an attempt to identify more discriminatory criteria for the species L. salivarius, beginning with pulsed-field gel electrophoresis (PFGE).
Plug preparation of undigested total genomic DNA of lactobacillus strains, macro-restriction digestion and PFGE were carried out as described by Claesson et al. (2006). Restriction of genomic DNA with SmaI allowed identification of 20 PFGE pattern types for the 32 strains (data not shown). However, assignment of strains to these PFGE types did not concord with subspecies allocation to any extent. To examine ribosomal gene phylogenies, total genomic DNA was isolated by a phenol/chloroform method (Flynn et al., 2002). The primers used for amplifying 16S rRNA genes were 27-F (5' -AGAGTTTGATCMTGGCTCAG) and 1492R (5'-GGTTACCTTGTTACGACTT) (Gurtler \& Stanisich, 1996). All PCR mixtures consisted of 1 ng genomic DNA, $2 \mathrm{mM}$ each dNTP, $2 \mu \mathrm{M}$ each primer, 0.25 U Pwo 


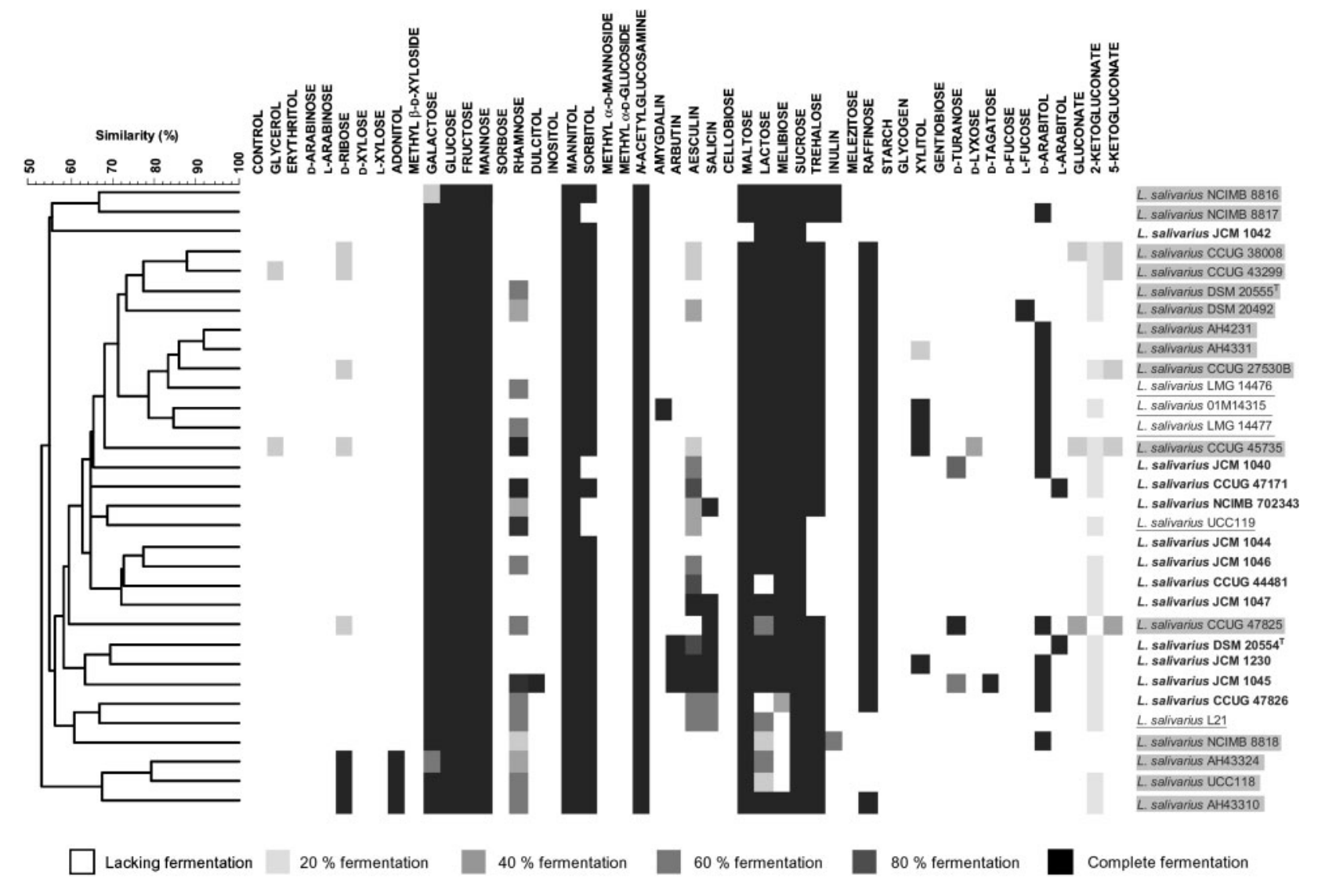

Fig. 1. Dendrogram showing the clustering of $32 \mathrm{~L}$. salivarius strains based on API 50 carbohydrate fermentation profiles. Numerical value for fermentation capability was defined according to the original colour changes in the API 50 test; values were converted to grey-scale shading for convenience. Names of strains that were previously characterized as $L$. salivarius subsp. salivarius are shaded in grey, while those of $L$. salivarius subsp. salicinius are shown in bold. Names of strains that are unassigned to a subspecies are underlined. Type strains are indicated by a superscript $\mathrm{T}$.

polymerase and $5 \mu \mathrm{l}$ Pwo polymerase buffer (Roche) in a total volume of $50 \mu$ l. PCRs were carried out in a DNA Engine thermal cycler (Bio-Rad). Amplification consisted of initial denaturation $\left(94^{\circ} \mathrm{C}, 2 \mathrm{~min}\right), 30$ cycles of denaturation $\left(94^{\circ} \mathrm{C}, 15 \mathrm{~s}\right)$, annealing $\left(45^{\circ} \mathrm{C}, 30 \mathrm{~s}\right)$ and elongation $\left(72{ }^{\circ} \mathrm{C}, 120 \mathrm{~s}\right)$ and a final elongation step $\left(72{ }^{\circ} \mathrm{C}, 7 \mathrm{~min}\right)$. PCR products were purified using the High Pure PCR purification kit (Roche Diagnostics) and then sequenced by MWG Biotech (Ebersberg, Germany). Apart from the 16S rRNA gene sequence of strain UCC118, which was obtained from the genome sequencing project (Claesson et al., 2006; GenBank accession number CP000233), we sequenced the 16S rRNA genes of strains DSM $20555^{\mathrm{T}}$ (type strain of $L$. salivarius subsp. salivarius), AH4331, NCIMB 8817 and NCIMB 702343. The 16S rRNA gene sequences of some other strains used in this study were already available, including those of strains JCM 1042 (GenBank accession no. AY137584), JCM 1044 (AY137585), JCM 1045 (AY137586), JCM 1046 (AY137587), JCM 1047 (AY137588), JCM 1230 (AY137588) and 01M14315 (AF420311). Of the 12 strains mentioned above, four strains represent the salivarius subspecies and seven strains represent the salicinius subspecies, while one strain was unassigned.

The L. salivarius UCC118 genome contains seven rRNA operons (Claesson et al., 2006). The sequences of the 16S$23 \mathrm{~S}$ spacer region of the seven rRNA operons are identical. Although polymorphisms exist between the different $16 \mathrm{~S}$ rRNA gene copies (three 16S rRNA sequences have one, two and five nucleotide differences compared with the majority consensus), they occur in different positions. We amplified and sequenced the PCR product based on the 16S rRNA genes of $L$. salivarius UCC118 and obtained a sequence chromatogram identical to the consensus, suggesting that sequences of PCR products could be used directly as representative of the consensus sequence of that strain. The 16S rRNA gene sequences of four strains (JCM 1042, JCM $1044, \mathrm{DSM} 20555^{\mathrm{T}}$ and $\left.01 \mathrm{M} 14315\right)$ were identical to that of strain UCC118, while the remaining seven strains (JCM 1045, JCM 1046, JCM 1047, JCM 1230, AH4331, NCIMB 8817 and NCIMB 702343) exhibited a single nucleotide difference compared with that of strain UCC118. 
Interestingly, we noticed that the sequences of $16 \mathrm{~S}$ rRNA genes of several $L$. salivarius strains isolated from dog (GenBank accession no. AB186340), horse (AY389802, AY389803, AY389804) and human vagina (AY112743) have more than two nucleotide differences compared with that of strain UCC118. However we could not incorporate these strains into this study, as they were not available to us.

We also amplified and sequenced the 16S-23S ISR of five strains from the salivarius subspecies (AH4231, AH4331, UCC119, DSM 20492 and DSM 20555 ${ }^{\mathrm{T}}$ ), seven strains from the salicinius subspecies (DSM 20554 ${ }^{\mathrm{T}}$, JCM 1040, JCM 1042, JCM 1045, JCM 1046, JCM 1047 and JCM 1230) and one unassigned strain (01M14315). The primers used were IGSL (5'-GCTGGATCACCTCCTTTC) and IGSR (5'CTGGTGCCAAGGCATCCA). All sequences were either identical or differed by a single nucleotide. Song et al. (2000) reported that the 16S-23S ISR for the two subspecies type strains of L. salivarius (strains DSM 20554 ${ }^{\mathrm{T}}$ and DSM $20555^{\mathrm{T}}$ in Fig. 1) were identical. Our results further show that 16S-23S ISR is not discriminatory for distinguishing strains of $L$. salivarius.

Phylogeny of groEL genes has provided superior discriminatory power when applied to many organisms, including Streptococcus suis (Brousseau et al., 2001), Streptococcus mutans (Hung et al., 2005), pathogenic Enterococcus species (Tsai et al., 2005) and Bifidobacterium species (Ventura et al., 2004). Phylogeny of the groEL gene was exploited to identify novel subspecies in L. plantarum (Bringel et al., 2005) and Lactobacillus delbrueckii (Dellaglio et al., 2005). The groEL and groES genes of $32 \mathrm{~L}$. salivarius strains including the reference strain UCC118 were amplified using primers LSL_1212groS_F2 (5'-AAACCATTAGGAGATCGCGTT) and LSL_1211groL_R2 (5'-ATCATACCGCCCATACCTG). Consideration of the groES gene sequences alone provided poor discrimination (not shown). However, the sequences of groEL provided a more reliable basis for constructing a phylogenetic tree.

The groEL sequences were aligned using CLUSTAL W (Thompson et al., 1994) using default parameters. Phylogenetic trees were built by using either neighbourjoining and maximum-parsimony in MEGA version 3.1 (Kumar et al., 2004) or the method of maximum-likelihood implemented in PhyML (Guindon \& Gascuel, 2003) with the general time-reversible plus gamma $(\mathrm{GTR}+\gamma)$ model (Fig. 2). The phylogenetic trees generated by the different methods exhibited similar topologies, with only minor differences in the positions of some closely related strains. All phylogenetic trees contained three clear divisions, but the maximum divergence seen was modest (24 nucleotides over $1.5 \mathrm{~kb}$ of DNA sequence compared). The two type strains, DSM 20554 ${ }^{\mathrm{T}}$ (subspecies salicinius) and DSM $20555^{\mathrm{T}}$ (subspecies salivarius), were separated into distinct branches, each of which comprised a mixture of strains from the two subspecies. The clade containing the $L$. salivarius subsp. salivarius type strain DSM $20555^{\mathrm{T}}$ was further subdivided into two well-separated clusters. Among the clades separated, the mean value of the $\mathrm{G}+\mathrm{C}$ content of the clade containing the $L$. salivarius subsp. salivarius type strain DSM $20555^{\mathrm{T}}(36 \cdot 32 \mathrm{~mol} \%)$ was the highest, followed by the clade containing strain AH4231 (36.2 mol\%) and the clade containing the $L$. salivarius subsp. salicinius type strain DSM $20554^{\mathrm{T}}(36 \cdot 07 \mathrm{~mol} \%)$. This suggests that the three groEL clades experienced unequal nucleotide substitution rates during evolution. However, in contrast to other studies which have provided polyphasic evidence supporting Lactobacillus subspecies discrimination (e.g. Bringel et al., 2005), there was no concordance of the groEL-based phylogeny with phenotypic traits and the overall level of nucleotide divergence was low. Furthermore, the majority of the nucleotide substitutions were silent, and trees constructed on the basis of amino acid sequences had low bootstrap confidence values (not shown).

In conclusion, members of a diverse panel of $L$. salivarius strains, from multiple culture collections, source animals and isolation dates, could be divided into clades and clusters only on the basis of groEL gene phylogeny, a very discriminatory technique. A variety of other methodologies, including rRNA gene comparison and carbohydrate fermentation profiles, did not provide any evidence to support the pragmatic subdivision of this species. We therefore propose that the infraspecific division of Lactobacillus salivarius cannot be justified and should be discontinued. There follows an emended description of Lactobacillus salivarius, based on previous phenotypic analyses (Mitsuoka, 1969; Rogosa et al., 1953; Rogosa \& Sharpe, 1959), the genome sequence (Claesson et al., 2006) and the present study.

\section{Emended description of Lactobacillus salivarius Rogosa et al. 1953}

Cells are Gram-positive, non-motile, non-spore-forming, catalase-negative, nitrate reduction-negative rods with rounded ends, $0 \cdot 6-0.9 \times 1.5-5 \mu \mathrm{m}$, occurring singly and in chains of varying length. Sometimes, the cells are not exactly cylindrical and straight, but are instead slightly bent and swollen on one end. Colonies on MRS agar show a milky-white or light-brown colour and are convex, with a smooth edge and smooth surface. Mainly isolated from the mouth and intestinal tract of humans and hamster and the intestinal tract of chicken and swine. All strains grow at $45^{\circ} \mathrm{C}$, but not at $15^{\circ} \mathrm{C}$. Optimal growth temperature is $37^{\circ} \mathrm{C}$. Growth is stimulated in the presence of $5 \% \mathrm{CO}_{2}$. Glucose, fructose, mannose, mannitol, $N$-acetylglucosamine and sucrose are fermented by all strains. Galactose (30/32 strains tested), sorbitol (28/32), maltose (31/32), lactose (28/32), trehalose (26/32), raffinose (25/32) and melibiose $(27 / 32)$ are fermented by most strains, including the type strains of the two previously recognized subspecies. Rhamnose is fermented weakly by many strains. A few strains ferment ribose, adonitol, xylitol, D-arabitol, arbutin and salicin and hydrolyse aesculin, but the type strains of the two subspecies do not ferment pentoses or pentitols. Glycerol, erythritol, arabinose, xylose, sorbose, inositol, 


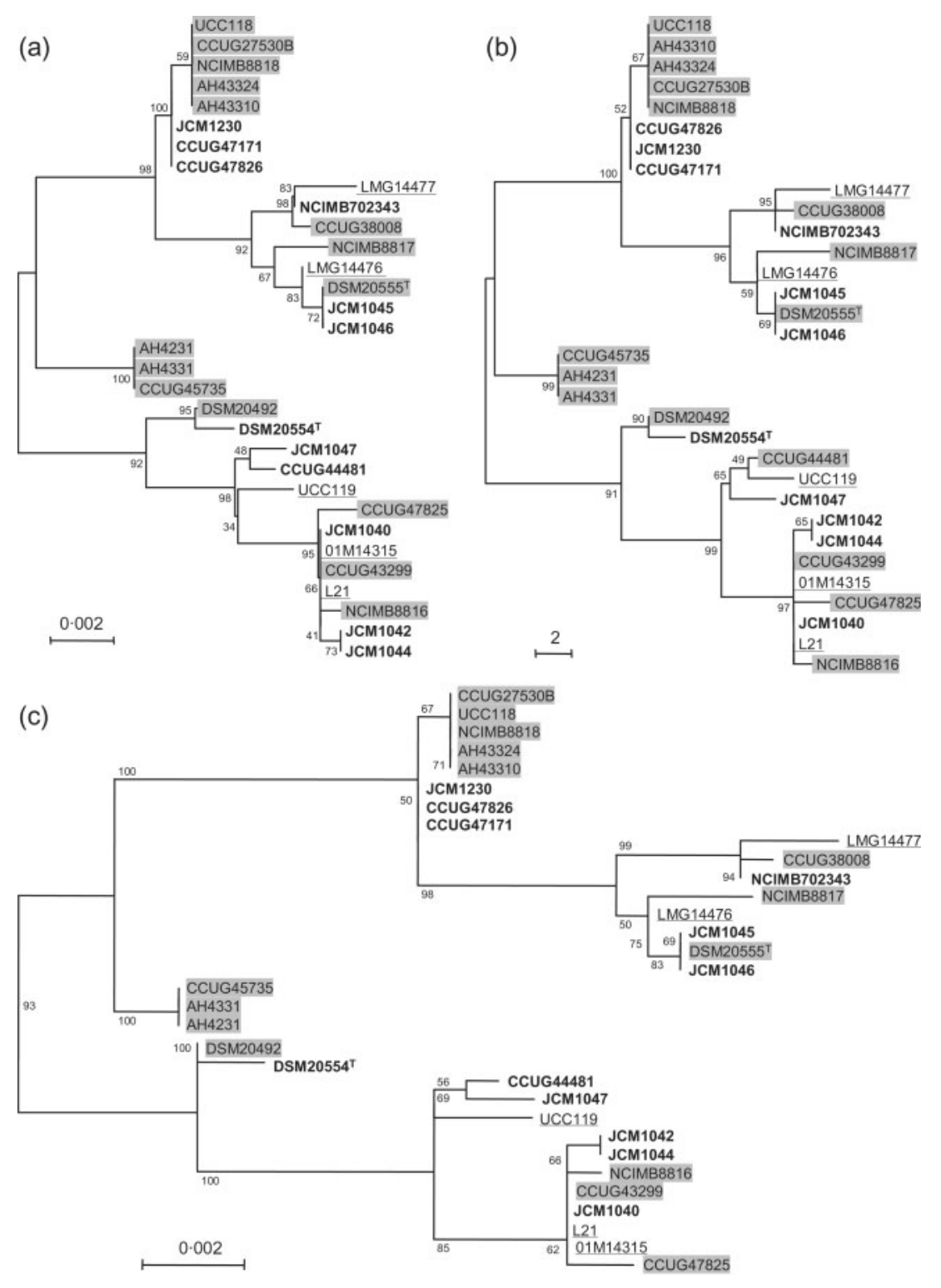

Fig. 2. Phylogenetic trees based on the groEL gene sequences of 32 L. salivarius strains built by using the neighbour-joining (a), maximum-parsimony (b) and maximumlikelihood (c) methods. Numbers at nodes correspond to bootstrap values based on 500 pseudoreplicates. Sequences have been deposited in GenBank; accession numbers are shown in Table 1. Previous subspecies affiliation is indicated as described in Fig. 1. Scale bars show genetic distance. methyl $\beta$-D-xyloside, methyl $\beta$-D-mannoside, methyl $\beta$-Dgluconoside, amygdalin, cellobiose, melezitose, starch, glycogen, gentiobiose and gluconate are not fermented. The species contains both homofermentative and facultatively heterofermentative strains. Most strains produce Llactic acid from available hexoses by homofermentation. Heterofermentative end products (lactic acid, acetic acid and ethanol) are produced from hexoses by some strains that can ferment ribose. Some strains have D-lactate dehydrogenase.

The DNA G + C content is 33-36 mol\%. Many strains of the species contain megaplasmids of sizes ranging from $100 \mathrm{~kb}$ to $380 \mathrm{~kb}$, as well as smaller plasmids. 16S rRNA gene sequences or $16 \mathrm{~S}-23 \mathrm{~S}$ rRNA ISR sequences do not provide reliable discrimination between strains. Based on groEL phylogeny, the species can be separated into two major clades. Each clade contains one of the type strains of the two previously recognized subspecies, DSM $20554^{\mathrm{T}}$ (=ATCC $11742^{\mathrm{T}}=\mathrm{JCM} 1150^{\mathrm{T}}$ ) (the type strain of L. salivarius subsp. salicinius) and DSM $20555^{\mathrm{T}}$ (=ATCC $11741^{\mathrm{T}}=\mathrm{JCM}$ $1231^{\mathrm{T}}$ ) (the type strain of L. salivarius and of $L$. salivarius subsp. salivarius).

\section{Acknowledgements}

This research was supported by Science Foundation Ireland through a Centre for Science, Engineering and Technology award to the Alimentary Pharmabiotic Centre, UCC. We thank Kwok-Yung Yuen for strain 01M14315, Gerald W. Tannock for strain L21, Maki Kitahara for scientific communication, Dan Walsh for HPLC analysis and Axel Rau for translating German literature. 


\section{References}

Ahrne, S., Nobaek, S., Jeppsson, B., Adlerberth, I., Wold, A. E. \& Molin, G. (1998). The normal Lactobacillus flora of healthy human rectal and oral mucosa. J Appl Microbiol 85, 88-94.

Badet, M. C., Richard, B. \& Dorignac, G. (2001). An in vitro study of the $\mathrm{pH}$-lowering potential of salivary lactobacilli associated with dental caries. J Appl Microbiol 90, 1015-1018.

Bringel, F., Castioni, A., Olukoya, D. K., Felis, G. E., Torriani, S. \& Dellaglio, F. (2005). Lactobacillus plantarum subsp. argentoratensis subsp. nov., isolated from vegetable matrices. Int J Syst Evol Microbiol 55, 1629-1634.

Brousseau, R., Hill, J. E., Prefontaine, G., Goh, S. H., Harel, J. \& Hemmingsen, S. M. (2001). Streptococcus suis serotypes characterized by analysis of chaperonin 60 gene sequences. Appl Environ Microbiol 67, 4828-4833.

Claesson, M. J., Li, Y., Leahy, S. \& 12 other authors (2006). Multireplicon genome architecture of Lactobacillus salivarius. Proc Natl Acad Sci U S A 103, 6718-6723.

Dellaglio, F., Felis, G. E., Castioni, A., Torriani, S. \& Germond, J. E. (2005). Lactobacillus delbrueckii subsp. indicus subsp. nov., isolated from Indian dairy products. Int J Syst Evol Microbiol 55, 401-404.

Dunne, C., Murphy, L., Flynn, S. \& 12 other authors (1999). Probiotics: from myth to reality. Demonstration of functionality in animal models of disease and in human clinical trials. Antonie van Leeuwenhoek 76, 279-292.

Flynn, S., van Sinderen, D., Thornton, G. M., Holo, H., Nes, I. F. \& Collins, J. K. (2002). Characterization of the genetic locus responsible for the production of ABP-118, a novel bacteriocin produced by the probiotic bacterium Lactobacillus salivarius subsp. salivarius UCC118. Microbiology 148, 973-984.

Fujisawa, T. \& Mitsuoka, T. (1996). Homofermentative Lactobacillus species predominantly isolated from canine feces. J Vet Med Sci $\mathbf{5 8}$, 591-593.

Guindon, S. \& Gascuel, O. (2003). A simple, fast, and accurate algorithm to estimate large phylogenies by maximum likelihood. Syst Biol 52, 696-704.

Gurtler, V. \& Stanisich, V. A. (1996). New approaches to typing and identification of bacteria using the 16S-23S rDNA spacer region. Microbiology 142, 3-16.

Heilig, H. G., Zoetendal, E. G., Vaughan, E. E., Marteau, P., Akkermans, A. D. \& de Vos, W. M. (2002). Molecular diversity of Lactobacillus spp. and other lactic acid bacteria in the human intestine as determined by specific amplification of $16 \mathrm{~S}$ ribosomal DNA. Appl Environ Microbiol 68, 114-123.

Hung, W. C., Tsai, J. C., Hsueh, P. R., Chia, J. S. \& Teng, L. J. (2005) Species identification of mutans streptococci by groESL gene sequence. J Med Microbiol 54, 857-862.

Kandler, O. (1983). Carbohydrate metabolism in lactic acid bacteria. Antonie van Leeuwenhoek 49, 209-224.

Kandler, O. \& Weiss, N. (1986). Regular, nonsporing Gram-positive rods. In Bergey's Manual of Systematic Bacteriology, vol. 2, pp. 1208-1209. Edited by P. H. A. Sneath, N. S. Mair, M. E. Sharpe \& J. G. Holt. Baltimore: Williams \& Wilkins.

Koll-Klais, P., Mandar, R., Leibur, E., Marcotte, H., Hammarstrom, L. \& Mikelsaar, M. (2005). Oral lactobacilli in chronic periodontitis and periodontal health: species composition and antimicrobial activity. Oral Microbiol Immunol 20, 354-361.

Kumar, S., Tamura, K. \& Nei, M. (2004). MEGA3: integrated software for molecular evolutionary genetics analysis and sequence alignment. Brief Bioinform 5, 150-163.

Lapage, S. P., Sneath, P. H. A., Lessel, E. F., Skerman, V. B. D. Seeliger, H. P. R. \& Clark, W. A. (editors) (1992). International Code of Nomenclature of Bacteria (1990 Revision). Bacteriological Code. Washington, DC: American Society for Microbiology.

London, J. (1976). The ecology and taxonomic status of the lactobacilli. Annu Rev Microbiol 30, 279-301.

Mitsuoka, T. (1969). Comparative studies on lactobacilli from the faeces of man, swine and chickens. Zentralbl Bakteriol Orig 210, 32 51 (in German).

Molin, G., Jeppsson, B., Johansson, M. L., Ahrne, S., Nobaek, S., Stahl, M. \& Bengmark, S. (1993). Numerical taxonomy of Lactobacillus spp. associated with healthy and diseased mucosa of the human intestines. J Appl Bacteriol 74, 314-323.

Rogosa, M. \& Sharpe, M. E. (1959). An approach to the classification of the lactobacilli. J Appl Bacteriol 22, 329-340.

Rogosa, M., Wiseman, R. F., Mitchell, J. A., Disraely, M. N. \& Beaman, A. J. (1953). Species differentiation of oral lactobacilli from man including description of Lactobacillus salivarius nov. spec. and Lactobacillus cellobiosus nov. spec. J Bacteriol 65, 681-699.

Skerman, V. B. D., McGowan, V. \& Sneath, P. H. A. (1980). Approved lists of bacterial names. Int $J$ Syst Bacteriol 30, 225-420.

Song, Y., Kato, N., Liu, C., Matsumiya, Y., Kato, H. \& Watanabe, K. (2000). Rapid identification of 11 human intestinal Lactobacillus species by multiplex PCR assays using group- and species-specific primers derived from the 16S-23S rRNA intergenic spacer region and its flanking 23 S rRNA. FEMS Microbiol Lett 187, 167-173.

Thompson, J. D., Higgins, D. G. \& Gibson, T. J. (1994). CLUSTAL W: improving the sensitivity of progressive multiple sequence alignment through sequence weighting, position-specific gap penalties and weight matrix choice. Nucleic Acids Res 22, 4673-4680.

Tsai, J. C., Hsueh, P. R., Lin, H. M., Chang, H. J., Ho, S. W. \& Teng, L. J. (2005). Identification of clinically relevant Enterococcus species by direct sequencing of groES and spacer region. J Clin Microbiol 43, 235-241.

Ventura, M., Canchaya, C., Zink, R., Fitzgerald, G. F. \& van Sinderen, D. (2004). Characterization of the groEL and groES loci in Bifidobacterium breve UCC 2003: genetic, transcriptional, and phylogenetic analyses. Appl Environ Microbiol 70, 6197-6209.

Woo, P. C., Fung, A. M., Lau, S. K. \& Yuen, K. Y. (2002). Identification by $16 \mathrm{~S}$ rRNA gene sequencing of Lactobacillus salivarius bacteremic cholecystitis. J Clin Microbiol 40, 265-267. 